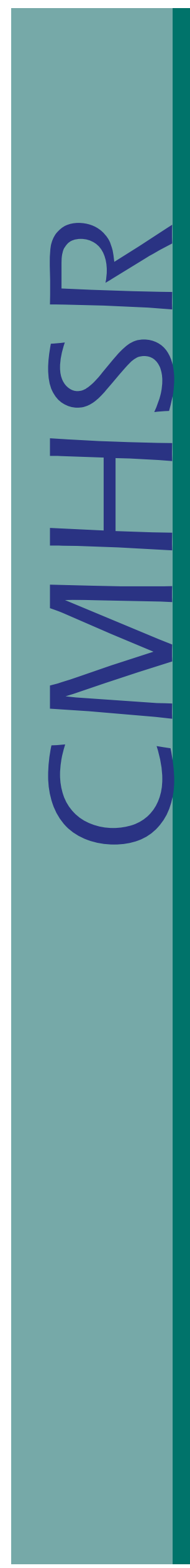

\title{
Strategies for Maximizing Medicaid to Fund Children's Mental Health Services
}

Kathleen Biebel, Ph.D., \& Judith Katz-Leavy, M.Ed.

$\mathrm{T}$ The President's New Freedom Commission on Mental Health suggests that mental health problems among children and adolescents constitute a public health crisis for the nation. ${ }^{1}$ Six to nine million children and adolescents in the United States have serious emotional disturbances, accounting for nine to 13 percent of all children. ${ }^{2}$ Despite this high prevalence, few children and adolescents in need of treatment receive behavioral health services, a finding particularly true for low-income and minority children. ${ }^{1}$ When children's mental health services are unavailable, unaffordable, or inappropriate, many young people end up caught in the child protection or juvenile justice systems. ${ }^{2}$ These underserved children and adolescents are at higher risk of adverse outcomes including unplanned pregnancies, school failure, out-of-home placements, difficulty with social relationships, and family disruptions. ${ }^{3}$

In 1992 Congress enacted the Comprehensive Community Mental Health Services Program for Children and their Families to reform existing mental health delivery systems that were often fragmented, uncoordinated and ineffectual into a single delivery system, a "system of care" for children and adolescents with serious emotional disturbance (SED). Federal grants provide up to six years of seed money to develop reform among systems serving children and adolescents most in need of behavioral health services. Grantees must secure non-federal matching contributions and demonstrate increased local and state contributions as federal funds decrease over the life of

(c) 2005 Center for Mental Health Services Research Department of Psychiatry University of Massachusetts Medical School the grant. One of the greatest challenges amongst grantee sites is securing this external funding, and ultimately achieving sustainability.

Medicaid, the largest payer of public health insurance after Medicare, does not traditionally reimburse for most of the services found in a system of care. For example, "wraparound," a community-based package of individualized services for children and families, can be found in programs across the country providing care to children with SED. Examples of such services include respite, mentoring, and support from parent-peers. Many of these more intensive community-based services that families report as most helpful to them, however, are often not covered by states in their Medicaid State Plans. ${ }^{4}$

This Issue Brief reviews findings from a University of Massachusetts Medical School (UMMS) CMHSR study exploring innovative and exemplary uses of Medicaid to fund systems of care for children with SED and their families. These findings will be presented in greater detail in a SAMHSA/ CMHS policy paper, to be released in early 2006.

\section{Study Goals}

The goals of this study were to identify and describe innovative and exemplary uses of Medicaid to fund system of care services across the Comprehensive Community Mental Health Services Program for Children and their Families grantee sites and to assess these practices in the context of the State Medicaid Plans. These findings identified creative and pioneering approaches to using Medicaid as a mechanism to fund system of care services for children with SED and their families. Results include strategies useful to state-level systems administrators and grantee sites program directors in developing sustainability plans.

\section{Methods}

In November 2003, Principal Investigators and Project Directors from 92 active and graduated grantee sites were surveyed regarding their use of 
Medicaid. The survey asked about grantees' use of Medicaid, and asked grantees if they believed they were innovative in their use of Medicaid to fund system of care services. Fiftyfour surveys were collected from November 2003 to May 2004 , for a $59 \%$ response rate.

Six grantee sites were selected for site visits to gather more detailed information about financing and sustainability. A National Advisory Group comprised of experts in children's mental health, Medicaid, and financing provided guidance and feedback to study investigators in this process. All selected sites: a) self-identified as innovative in using Medicaid; b) nominated themselves to participate in site visits to gather further information regarding the use of Medicaid; and c) were recommended for participation by a member of the National Advisory Group. Grantee sites included: the Dawn Project, Indiana; the Burlington Partnership, New Jersey; Community Connections for Families, Pennsylvania; Bridges, Kentucky, Spirit of Caring, California, and Partnerships with Families/ Transitions, Missouri.

Study investigators developed a semi-structured interview protocol to be administered during site visits to capture information on relevant dimensions to Medicaid, financing and sustainability. The protocol was developed in consultation with grantee sites and the National Advisory Group, and was reviewed and approved for use by the UMMS Institutional Review Board. From September 2004 through January 2005, study investigators visited each grantee site for two days and interviewed grantee sites' Principal Investigators and/or Program Directors, grantee site finance administrators, family members, partner agencies, provider agencies and, where appropriate, state/county Medicaid and/or Children's Health Insurance Program (CHIP) mental health liaisons. On the last day of the visit, investigators presented a summary case study report for feedback. Case studies were revised after the site visit and additional feedback from program staff and participants was requested and integrated via e-mail and telephone. Qualitative data from the interview protocol were content-analyzed after coding for themes.

\section{Results}

Preliminary analyses of the qualitative case study data suggest grantee sites use a variety of strategies to maximize Medicaid reimbursement. Many strategies were identified by all or most grantee sites while others were unique to specific sites. Strategies include:

- Building relationships with key stakeholders to think strategically about using Medicaid;

- Developing infrastructures, e.g. information technology systems, to facilitate interactions with Medicaid;
- Educating community providers through technical assistance and trainings on how to bill Medicaid;

- Establishing and maintaining Medicaid eligibility for all incoming children and their families;

- Increasing funding contributions from multiple partner agencies to maximize State Medicaid match to access the full federally-funded portion (FFP);

- Establishing household-of-one designation to facilitate access to Medicaid for out-of-home children based on the child's, not family's, income;

- Amending State Medicaid Plan language to include wraparound services; and,

- Seeking expert consultation to educate key stakeholders on the language of system of care services and Medicaid.

\section{Conclusions}

These preliminary findings are the first step in understanding how the federal Comprehensive Community Mental Health Services Program for Children and their Families grantee sites use Medicaid to pay for services that have not traditionally been reimbursed through this funding mechanism. This knowledge will be useful to other grantee sites and systems of care programs as they strive to achieve sustainability, and provide services to children and families in need for as long as necessary.

\section{References}

1. President's New Freedom Commission on Mental Health Subcommittee on Children and Family Summary Report. February 5, 2003. http://www.mentalhealthcommission.gov/subcommittee/ children_family020703.doc.

2. U.S. Department of Health and Human Services (1999). Mental Health: A Report of the Surgeon General. U.S. Department of Health and Human Services, Substance Abuse and Mental Health Services Administration, Center for Mental Health Services, National Institutes of Health, National Institute of Mental Health. Rockville, MD.

3. Villani, V.S. (2001). Children's services. In J.S. Talbott \& R.E. Hales (Eds.), Textbook of administrative psychiatry (2nd Ed.). Washington, DC: American Psychiatric Publishing.

4. Bazelon Center for Mental Health Law (1999). Making Sense of Medicaid for Children with Serious and Emotional Disturbance. Judge David L. Bazelon Center for Mental Health Law, Washington, DC.

Visit us on-line at www.umassmed.edu/cmhsr 